PRODUTO \& PRODUÇÃO, vol. 21, n.3, p.33-52. 2020

\title{
Aplicação de Métodos de Projeto no Desenvolvimento de Carrocerias de Ônibus: Um Estudo de Caso
}

\section{Application of Design Methods in the Development of Bus Bodies: A Case Study}

\author{
Dionatan Brizola Quevedo \\ Universidade de Passo Fundo - UPF \\ Aluno Mestrado Profissional em Projeto e Processos de Fabricação e Engenharia Mecânica \\ email: dionatan.quevedo@gmail.com
}

Márcio Walber (autor correspondente)

Universidade de Passo Fundo-UPF

Professor Mestrado Profissional em Projeto e Processos de Fabricação e Engenharia Mecânica email: mwalber@upf.br

\author{
Agenor Dias de Meira Junior \\ Universidade de Passo Fundo-UPF \\ Professor Mestrado Profissional em Projeto e Processos de Fabricação e Engenharia Mecânica \\ email: agenor@upf.br \\ Daniel Gasparin \\ Universidade de Passo Fundo - UPF \\ Aluno Mestrado Profissional em Projeto e Processos de Fabricação e Engenharia Mecânica \\ email: gasparin.daniel@hotmail.com
}

Recebido em 21/04/2020. Aceito em 10/06/2020. 


\title{
Resumo
}

Em virtude da grande importância de se desenvolver um produto no momento certo e que desperte o interesse do mercado, torna-se necessário a implantação de um procedimento eficaz para a concepção de boas soluções. O presente trabalho detalha um estudo de caso do desenvolvimento uma carroceria de ônibus rodoviário, no qual sua nova configuração modular possibilitou uma redução no tempo de projeto e montagem, elevando a padronização da estrutura de $30,5 \%$ para $70,4 \%$, permitindo que a mesma carroceria seja montada em diferentes chassis com a utilização de pequenos blocos construtivos. Para o desenvolvimento do novo conceito foram aplicados métodos e ferramentas de projeto, desde o planejamento e concepção inicial, até o detalhamento final, promovendo maior assertividade e organização, evidenciando que a utilização de métodos e técnicas no ciclo de desenvolvimento do produto proporcionam produtos inovadores e eficazes.

Palavras-chave: Projeto de carrocerias de ônibus. Métodos para projeto e desenvolvimento de produtos. Projeto modular.

\begin{abstract}
Because of the great importance of developing a product at the right time and to arouses the interest of the market, it is necessary to implement an efficient procedure for the design of good solutions. The present work details a case study of development of a bus body, in which its new modular configuration allowed a reduction in the design and assembly time, increasing the standardization of the structure from $30,5 \%$ to $70,4 \%$, allowing the same body to be assembled on different chassis using small building blocks. For the development of the new concept, design methods and tools were applied, from the initial planning and design, to the final detailing, promoting greater assertiveness and organization, showing that the use of methods and techniques in the product development cycle provide innovative products and effective.
\end{abstract}

Keywords: Bus body design. Methods for product design and development. Modular design.

\section{Introdução.}

O produto ônibus cada vez mais vem sendo exigido pelo mercado em seu design, qualidade, segurança, custo-benefício, desempenho, prazo de entrega, entre outros. Cabe então ao departamento de Engenharia a tarefa de desenvolver o projeto dessa carroceria com excelência e com o menor tempo possível. Para tanto é preciso desenvolver ferramentas para acelerar o desenvolvimento desses projetos e seguir um método de trabalho que promova essa otimização.

O desenvolvimento de boas soluções necessita de um procedimento metódico flexível que seja aplicável e eficaz para empresa, exigindo de seus projetistas, além de seu conhecimento especializado, um trabalho sistemático, intensificando a capacidade de produção e invenção do mesmo (PAHL et al., 2013).

Back et al. (2008), explicam que a diversidade de requisitos dos consumidores resulta em uma grande variedade de produtos e uma produção difícil de planejar e controlar. Da mesma forma, as empresas encarroçadoras de ônibus disponibilizam diferentes modelos de chassis e opcionais que influenciam na configuração dos projetos.

Na prática existe uma dificuldade para entrega das carrocerias de ônibus no prazo solicitado pelo cliente e, muitas vezes é devido à complexidade de configuração desse pedido e a falta de padronização do produto, ou seja, o projeto está vinculado a características que impedem o adiantamento e o planejamento da fabricação. Para muitas empresas montadoras, como a própria indústria de ônibus, uma solução para esse tipo de problema é a elaboração de estruturas modulares. 
O objetivo deste trabalho é selecionar ferramentas e métodos para propor um procedimento de projeto no desenvolvimento de carrocerias e aplicar como estudo de caso na configuração de um projeto de um ônibus rodoviário de dois andares.

Atualmente, os métodos mais utilizados para desenvolvimento de produtos no Brasil, são os descritos por Pahl et al. (2013), que é derivado da norma de projeto alemã VDI 2221 (1987), Rozenfeld (2006), Baxter (2011) e Back (2008).

\section{Revisão de Literatura}

Pahl et al. (2013), apresentam um método de projeto dividido em quatro fases, onde a primeira etapa consiste em planejar e esclarecer o problema seguindo uma linha mestra de projeto, de modo que o resultado seja a elaboração de uma lista de requisitos, a qual serve de base para a segunda etapa. A concepção do projeto busca princípios de funcionamento através da estrutura de funções, gerando variantes de solução para cada subfunção, finalizando com a elaboração do anteprojeto. Só a partir da escolha da melhor solução por critérios pré-definidos que começa a fase de projeto preliminar. Conclui-se com a etapa de detalhamento e liberação da documentação para a produção. Estas etapas são mostradas na Figura 1.

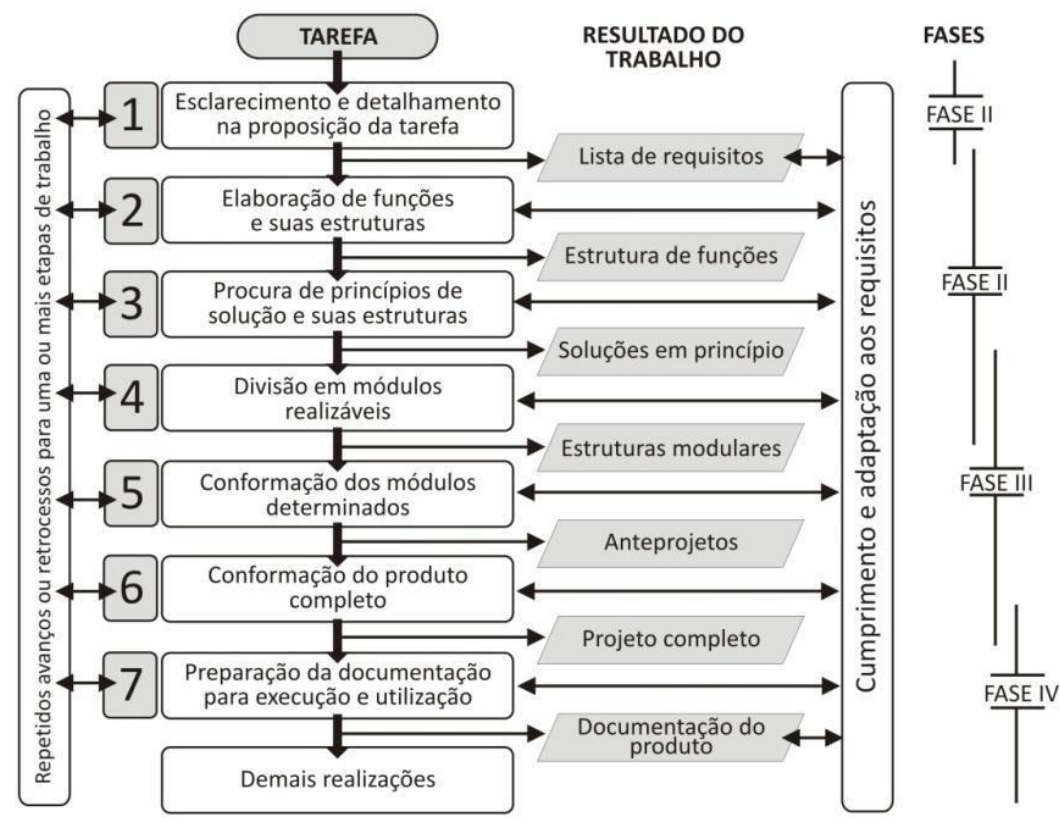

Figura 1 - Procedimento de projeto de Pahl et al. (2013), adaptado

Pahl et al. (2013) afirmam que a adoção de um sistema modular só é justificável se o produto é desenvolvido para uma função específica e passa a possuir variantes de função; por esse motivo, um produto que já existe no mercado pode ser reprojetado de forma modular.

De acordo Baxter (2011), o termo "modularidade" é adotado para descrever o uso de unidades comuns para criar uma variedade de produtos, pois o objetivo é identificar unidades independentes e normalizadas ou intercambiáveis para atender uma variedade de funções. É uma técnica bem difundida nas empresas modernas e é utilizada em projetos simples, como de brinquedos e móveis, e projetos complexos, como de automóveis e aviões. Assim, um dos principais objetivos da modularidade e do desenvolvimento de famílias de produtos é a customização em massa, isto é, a habilidade de prover produtos customizados por um valor similar aos produzidos em larga escala.

Back et al. (2008), possuem um modelo esquematizado composto por três macrofases decompostas em oito. São elas: planejamento do projeto, elaboração do projeto do produto e plano 
de manufatura e a implementação do lote piloto, envolvendo a execução do plano de manufatura na produção da empresa e o encerramento do projeto. Para o autor, existem duas categorias de produtos modulares quanto aos conceitos básicos: (i) módulos funcionais, que possuem um conceito abstrato e pode ser formado por uma ou mais funções e (ii) módulos construtivos, que são soluções físicas que incorporam um ou mais módulos funcionais. A Figura 2 mostra as fases de projeto propostas por Back et al. (2008).

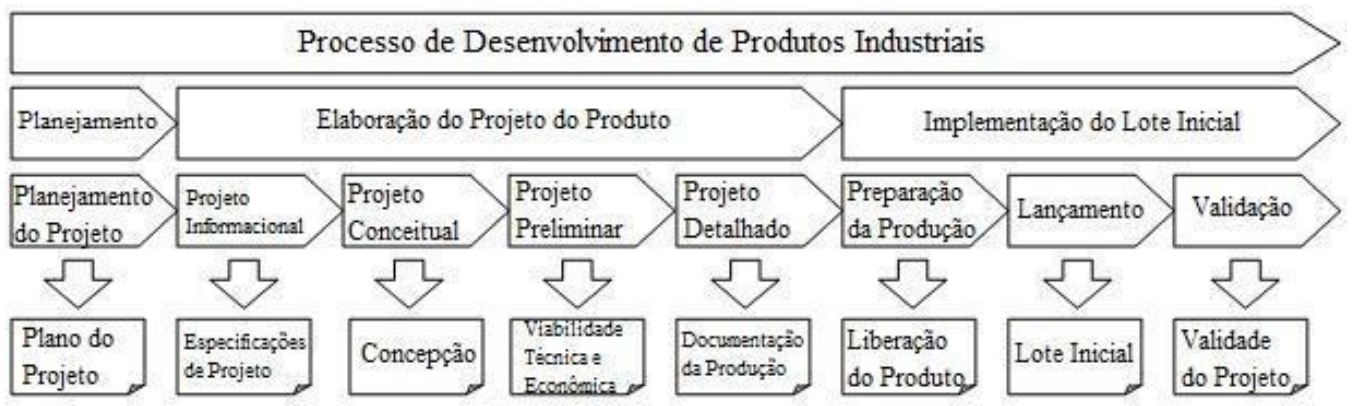

Figura 2 - Representação do processo de desenvolvimento integrado de produtos de Back et al. (2008), adaptado

Rozenfeld et al. (2006), descrevem em três fases o processo de projeto. Na fase informacional são coletadas as informações sobre normas, patentes, dados da concorrência e especificação dos requisitos para o produto, concluída com a avaliação econômica e financeira. A fase de projeto conceitual inicia com o esboço funcional do produto, desenvolvendo e avaliando as soluções propostas, definindo a arquitetura, ergonomia e estética do produto, finalizando com a definição do plano de processo e a atualização da viabilidade econômica e financeira do projeto. Como última fase, denominada projeto detalhado, apresenta o fechamento do mesmo com os cálculos, desenhos, especificações de tolerâncias, configuração do produto, codificação dos sistemas, subsistemas e componentes, desenvolvimento de fornecedores, planejamento do processo de fabricação, testes e homologações (Figura 3). Mesmo com a finalização do desenvolvimento, sua metodologia engloba a fase de pós-desenvolvimento, com suporte técnico e monitoramento do ciclo de vida do produto.

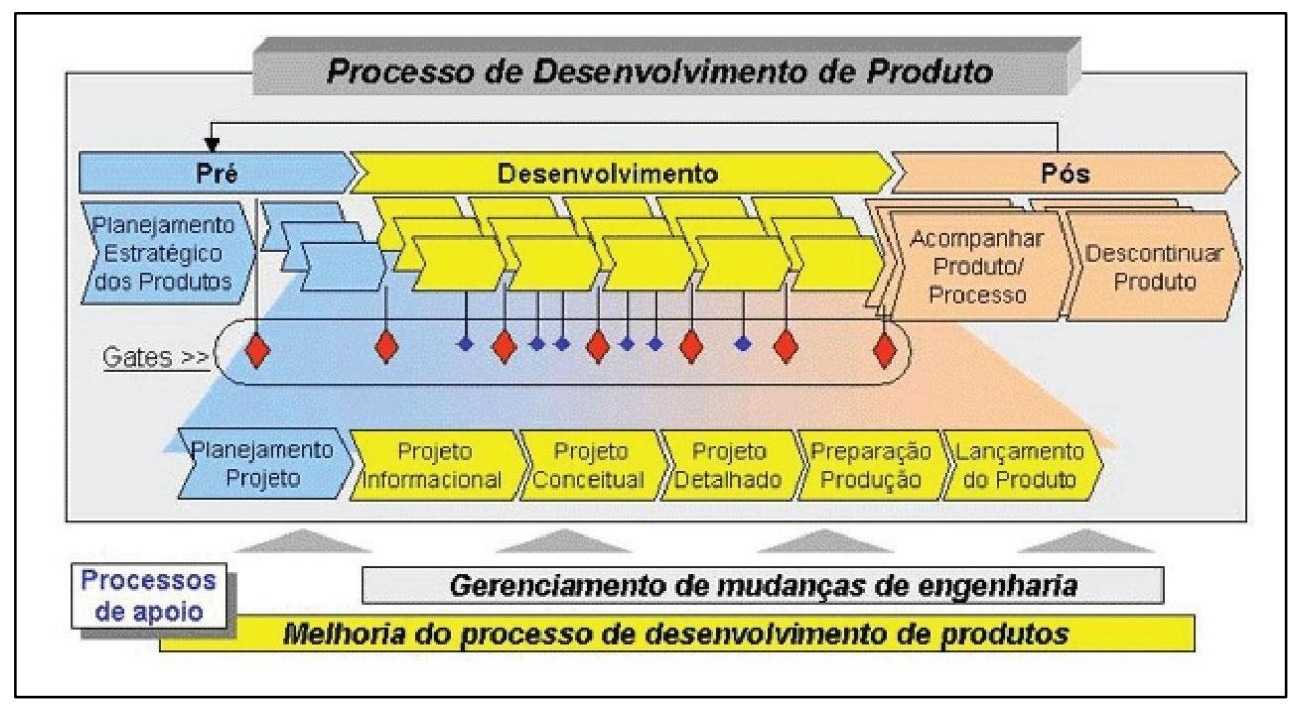

Figura 3 - Método Proposto por Rozenfeld et al. (2006)

Baxter (2000), apresenta um método chamado funil de decisões, qual suas etapas representam uma sequência útil e sensível no processo de desenvolvimento de novos produtos, onde os riscos de fracasso do produto são progressivamente reduzidos à medida que as decisões hierarquizadas são tomadas. Através da Figura 4 é possível perceber um aumento substancial do compromisso financeiro, quando o processo de desenvolvimento avança. 


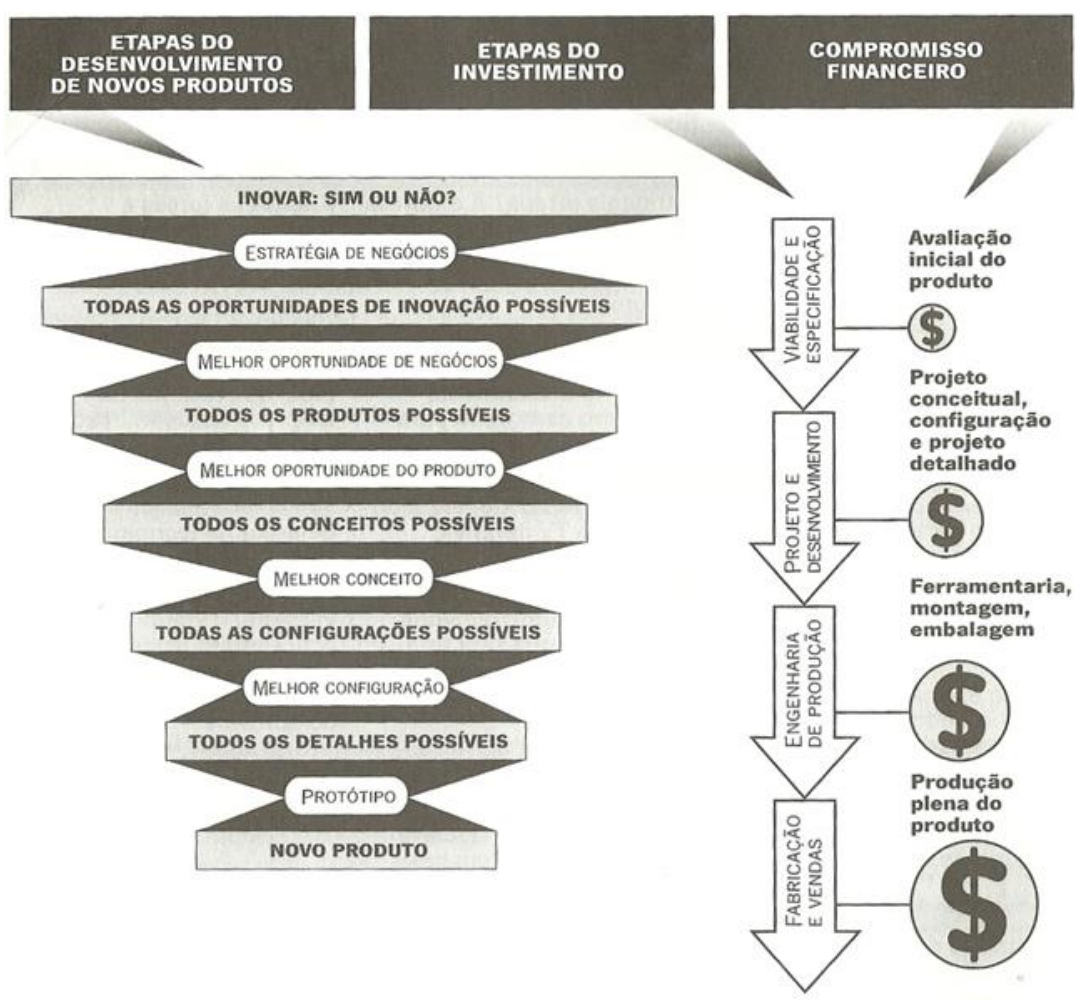

Figura 4 - Funil de decisões proposto por Baxter (2000)

Segundo Ullman (2003), o processo de projeto varia de produto para produto e de indústria para indústria. No entanto, é possível construir um fluxo de atividades que devem ser realizadas nos projetos de uma maneira geral.

Conforme Baldwin e Clarck (2000), existem três passos para conceber um projeto modular, reunir as regras de projeto para todo o sistema, desenvolver em paralelo os módulos e por fim, os sistemas de integração e testes. Os autores destacam também a importância de utilizar os seis operados modulares no processo de modularização. São eles: dividir, substituir, adicionar, excluir, inverter e conduzir.

Segundo Kamrani e Salhieh (2002), um sistema modular pode ser desenvolvido através da decomposição do sistema em elementos funcionais básicos, identificando a função física de cada elemento. Posteriormente estes elementos são agrupados através de suas semelhanças funcionais e características físicas. Para o correto mapeamento desses elementos é útil a construção de uma matriz, onde será descrito o relacionamento entre o componente e a função.

Como exemplo de aplicação na indústria de ônibus, Viero (2013), utilizou técnicas de modularidade no projeto de uma carroceria de ônibus rodoviário intermunicipal, concebendo uma carroceria aproximadamente $77 \%$ determinada, ou seja, sem necessidade de alteração do projeto devido a suas variantes de configuração ou customizações derivadas do cliente. Também obteve uma redução de $11 \%$ no tempo de montagem total da estrutura.

Existe uma grande dificuldade de escolher qual método/autor utilizar na resolução de problemas projetuais na concepção de novos produtos ou mesmo na melhoria de projetos anteriores. Quanto a forma mais adequada ao desenvolvimento do produto como ao modo de pensar do projetista que está à frente do projeto, costuma-se dizer que "a melhor metodologia é a própria" (GOMEZ, 2003, p. 33). Apesar desta afirmação, pode-se constatar que as fases de desenvolvimento projetual, de certa forma, são semelhantes, pois são apresentados na literatura posicionamentos, fases e abordagens diferentes, porém, mantém-se um esboço geral de problema, análise, criação e execução, de forma clara, ou subentendida em um só nome.

Para a concepção do projeto da carroceria de ônibus apresentada neste estudo foi utilizado o procedimento de projeto proposto por Pahl et al. (2013). Justifica-se a escolha deste método pelo fato 
do mesmo ser sintetizado em 4 fases, englobando principalmente o período da projetação, e ilustrando ferramentas de projetos que auxiliam o projetista mecânico nas tomadas de decisões, durante as diferentes etapas de desenvolvimento.

\section{Desenvolvimento do Projeto da Carroceria.}

O presente trabalho foi aplicado no setor de Engenharia de uma empresa encarroçadora de ônibus e para o desenvolvimento do projeto foi utilizada a metodologia descrita por Pahl et al. (2013), qual possui uma abordagem mais voltada para a área técnica, dividindo o projeto em quatro fases de maneira sucinta, porém eficaz.

\subsection{Planejamento e esclarecimento da tarefa (Fase 1).}

Modificações a serem feitas custam pouco no início do desenvolvimento, onde a pesquisa ocorreu apenas no papel e os trabalhos de projeto consistem em desenhos e modelos de baixo custo, aumentando à medida que o processo avança. Portanto, o processo inicia com definição das tarefas, pesquisa de mercado, de normas, da concorrência, especificação dos requisitos para o produto e o planejamento. Com o objetivo de identificar e analisar os principais problemas enfrentados no projeto atual da carroceria, foi elaborada uma matriz para o mapeamento de sua estrutura. A Figura 5 apresenta os principais conjuntos da estrutura da carroceria, estes também representados na Tabela 1, a qual cruza as informações com as configurações do pedido de vendas. As células destacadas com "X" indicam que o conjunto sofre influência da respectiva configuração.

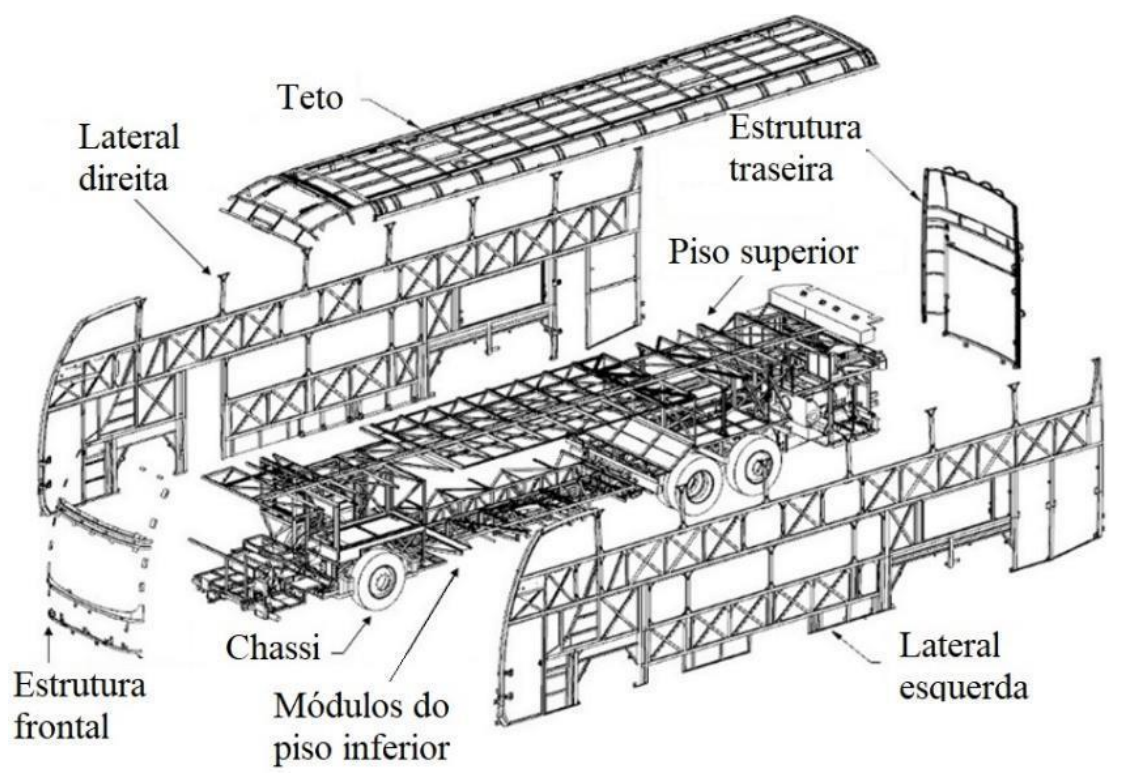

Figura 5 - Principais conjuntos da carroceria

Analisando a Tabela 1 é possível verificar a grande influência das configurações de venda na determinação da estrutura, evidenciando que o projeto atual está diretamente conectado a essas configurações, com destaque para o modelo de chassi, que dos 16 conjuntos do projeto impacta em pelo menos 15 .

Estas configurações de venda por sua vez, estão com um alto número de opcionais, como é baixo o número de conjuntos que podem ser reaproveitados de um pedido para o outro, surge então uma grande variedade de conjuntos que desempenham a mesma função na carroceria, aumentando o tempo para configurar esse projeto, dificultando e limitando o processo de montagem. 
Tabela 1 - Influência das configurações de venda na estrutura da carroceria

\begin{tabular}{|c|c|c|c|c|c|c|c|c|c|c|}
\hline \multirow[b]{2}{*}{$\begin{array}{c}\text { Estrutura } \\
\text { Principal } \\
\text { da } \\
\text { Carroceria }\end{array}$} & \multicolumn{10}{|c|}{ Configurações de Vendas } \\
\hline & $\begin{array}{l}\text { Model } \\
\text { o de } \\
\text { Chassi }\end{array}$ & $\begin{array}{c}\text { Tipo } \\
\text { de } \\
\text { Esca } \\
\text { da }\end{array}$ & $\begin{array}{c}\text { Tipo } \\
\text { de } \\
\text { Poltro } \\
\text { na } \\
\text { Inferio } \\
\text { r }\end{array}$ & $\begin{array}{c}\text { Tipo } \\
\text { de } \\
\text { Poltro } \\
\text { na } \\
\text { Superi } \\
\text { or }\end{array}$ & $\begin{array}{l}\text { Ar - } \\
\text { Condi } \\
\text { c. }\end{array}$ & $\begin{array}{l}\text { WC } \\
\text { no } \\
\text { Salão } \\
\text { Inferi } \\
\text { or }\end{array}$ & $\begin{array}{c}\text { Cam } \\
\text { a }\end{array}$ & $\begin{array}{l}\text { Rodomo } \\
\text { ça Salão } \\
\text { Inferior }\end{array}$ & $\begin{array}{l}\text { Móve } \\
\text { is } \\
\text { Salão } \\
\text { Inferi } \\
\text { or }\end{array}$ & $\begin{array}{l}\text { Distribuiç } \\
\text { ão de } \\
\text { Poltronas }\end{array}$ \\
\hline $\begin{array}{l}\text { Módulo } \\
\text { Inferior }\end{array}$ & $\mathrm{X}$ & $\mathrm{X}$ & $\mathrm{X}$ & & & & $\mathrm{X}$ & $\mathrm{X}$ & $\mathrm{X}$ & \\
\hline $\begin{array}{l}\text { Módulo } \\
\text { Traseiro }\end{array}$ & $\mathrm{X}$ & & $\mathrm{X}$ & & & & & & & $\mathrm{X}$ \\
\hline $\begin{array}{l}\text { Módulo } \\
\text { do Entre- } \\
\text { Eixos }\end{array}$ & $\mathrm{X}$ & & $\mathrm{X}$ & & & $\mathrm{X}$ & & & & $\mathrm{X}$ \\
\hline $\begin{array}{c}\text { Preparaçã } \\
\text { o Chassi }\end{array}$ & $\mathrm{X}$ & & $\mathrm{X}$ & & & & & & & \\
\hline $\begin{array}{c}\text { Base } \\
\text { Superior }\end{array}$ & $\mathrm{X}$ & $\mathrm{X}$ & & $\mathrm{X}$ & $\mathrm{X}$ & & & & & $\mathrm{X}$ \\
\hline $\begin{array}{l}\text { Lateral } \\
\text { Direita }\end{array}$ & $\mathrm{X}$ & & $\mathrm{X}$ & & & & & & & $\mathrm{X}$ \\
\hline $\begin{array}{c}\text { Lateral } \\
\text { Esquerda }\end{array}$ & $\mathrm{X}$ & & $\mathrm{X}$ & & & $\mathrm{X}$ & & & & $\mathrm{X}$ \\
\hline Teto & & & & & $X$ & & & & & \\
\hline $\begin{array}{l}\text { União } \\
\text { Casulo } \\
\text { Chassi }\end{array}$ & $\mathrm{X}$ & $\mathrm{X}$ & & & & & & & & $\mathrm{X}$ \\
\hline $\begin{array}{l}\text { Chap. } \\
\text { Interno } \\
\text { Superior }\end{array}$ & $\mathrm{X}$ & $\mathrm{X}$ & & $\mathrm{X}$ & & & & & & $\mathrm{X}$ \\
\hline $\begin{array}{l}\text { Chap. } \\
\text { Interno } \\
\text { Inferior }\end{array}$ & $\mathrm{X}$ & & $\mathrm{X}$ & & & $\mathrm{X}$ & & & $\mathrm{X}$ & $\mathrm{X}$ \\
\hline $\begin{array}{l}\text { Cabine } \\
\text { Motorista }\end{array}$ & $\mathrm{X}$ & $\mathrm{X}$ & & & & & & & & \\
\hline $\begin{array}{c}\text { Túnel } \\
\text { Inferior }\end{array}$ & $\mathrm{X}$ & $\mathrm{X}$ & & & & & $\mathrm{X}$ & $\mathrm{X}$ & $\mathrm{X}$ & \\
\hline $\begin{array}{l}\text { Chapeamen } \\
\text { to Externo }\end{array}$ & $\mathrm{X}$ & & & & & $\mathrm{X}$ & & & & $\mathrm{X}$ \\
\hline Portinholas & $\mathrm{X}$ & & & & & & & & & $X$ \\
\hline $\begin{array}{c}\text { Revestimen } \\
\text { to do } \\
\text { Bagageiro }\end{array}$ & $\mathrm{X}$ & & $\mathrm{X}$ & & $\mathrm{X}$ & & & & & $\mathrm{X}$ \\
\hline Total & 15 & 6 & 8 & 2 & 3 & 4 & 2 & 2 & 3 & 11 \\
\hline
\end{tabular}

Realizou-se uma pesquisa para verificar a contribuição em vendas de cada modelo de chassis, buscando delinear as características que mais influenciam o projeto. A Figura 6a apresenta um gráfico da distribuição dos modelos de chassis em vendas para a carroceria. Analisando a pesquisa de mercado, é possível perceber que aproximadamente $97 \%$ da participação em vendas da carroceria é composta basicamente por três famílias de chassis: Mercedes-Benz O500 RSD, Scania IB e Volvo B11R. Portanto, o desenvolvimento foi voltado para esses três modelos, direcionando o projeto para contemplar a maior porcentagem da expectativa de vendas de carrocerias. 
Como etapa do início do desenvolvimento, foi elaborada uma linha mestra com a função de especificar características para o planejamento do projeto, para que, por meio do atendimento de suas condicionantes sejam determinados os requisitos que deverão ser observados durante o desenvolvimento. A Figura $6 \mathrm{~b}$ ilustra a linha mestra, derivada das condicionantes gerais para projeto e com base nas principais características e necessidades do mercado para a construção de carrocerias.

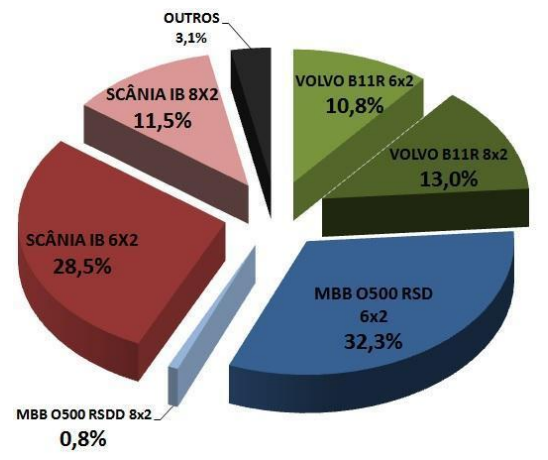

(a)

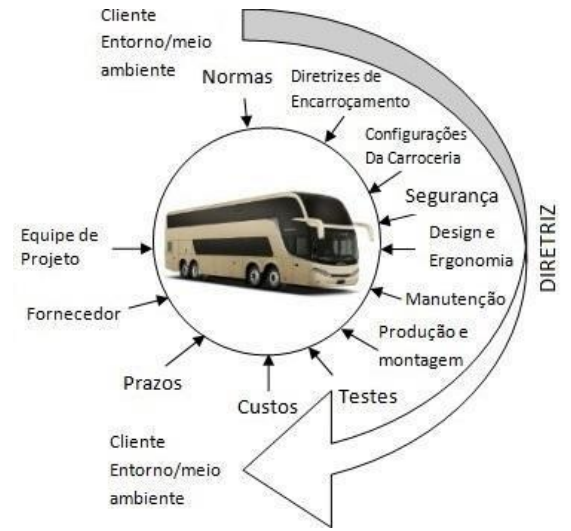

(b)

Figura 6 - Contribuição dos modelos de chassi em vendas para a carroceria e linha mestra do projeto

Estabelecer as especificações de projeto é uma das tarefas mais importantes e difíceis de todo o processo de desenvolvimento, pois elas servem de diretrizes para todas as demais fases (PAHL et al, 2013). A Tabela 2 apresenta uma parte da lista de requisitos elaborada para o projeto.

$\mathrm{Na}$ primeira coluna estão as condicionantes da linha mestra seguida de seus respectivos requisitos. O requisito pode ser classificado como uma exigência "E", ou apenas desejável "D", este último permitindo o seu cumprimento ou não. A última coluna determina os responsáveis pela execução. 
Tabela 2 - Lista de requisitos para o projeto

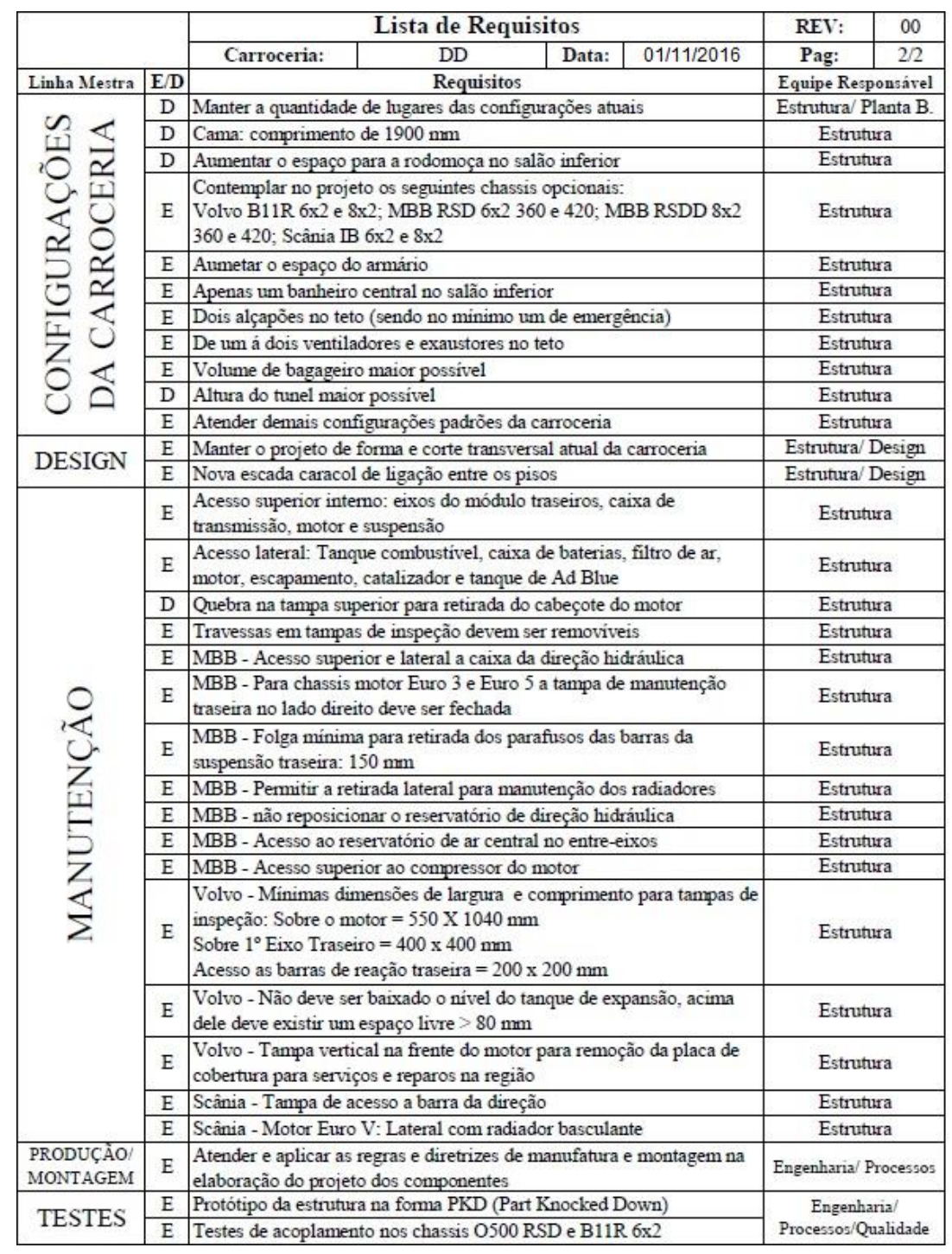

\subsection{Concepção (Fase 2).}

Esta fase tem início com uma abstração para a identificação e esclarecimento dos principais problemas de forma neutra a solução, para a auxiliar na determinação da função global, que é a relação geral e desejada entre a entrada e a saída de um sistema, com a finalidade de cumprir uma tarefa .

Para a concepção de um projeto modular é necessário dividir um sistema em módulos, de modo que as características do projeto e as tarefas sejam dependentes dentro do módulo e independentes entre os módulos. Esse sistema modular pode ser desenvolvido por meio da decomposição da estrutura em elementos funcionais básicos, identificando a função física de cada um, que é basicamente atuar como elementos de ligação, dando forma ao projeto da estrutura lateral da carroceria.

Portanto, para uma análise mais minuciosa das regiões da carroceria e seu relacionamento com as configurações de venda, a estrutura lateral foi dividida em regiões e sub-regiões conforme ilustrada na Figura 7, cada cor delimita um agrupamento de componentes que desempenham a mesma função. 


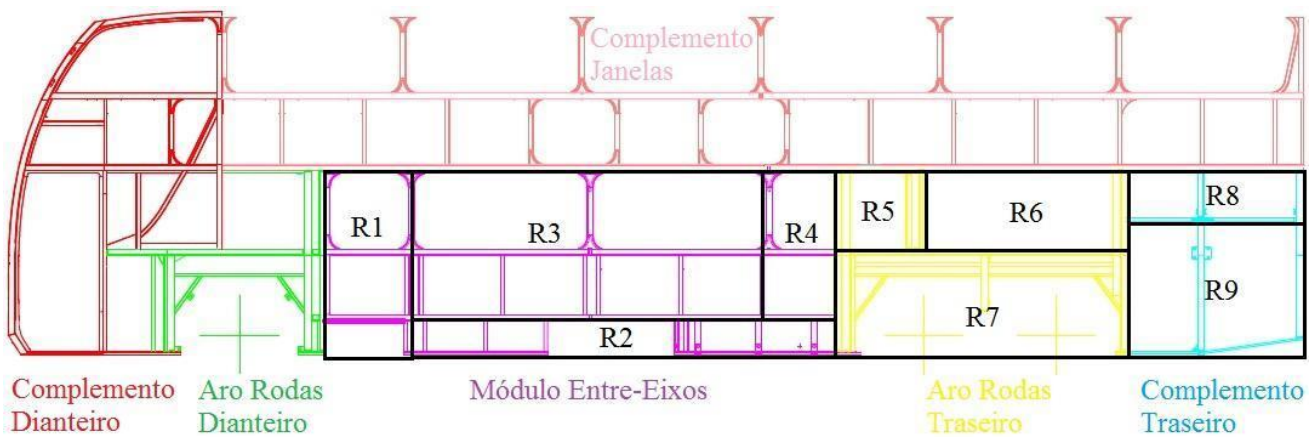

Figura 7 - Lateral dividida em regiões

Para o correto mapeamento desses elementos é útil a construção de uma matriz, onde será descrito o relacionamento entre o componente e a função. Migrando as configurações de venda da Tabela 1 para uma nova matriz representada pela Tabela 3, é possível refazer o mapeamento dos componentes da lateral representados na Figura 7, destacando novamente com um " $\mathrm{X}$ " as regiões as quais são modificadas pelas configurações de venda correspondentes.

Tabela 3 - Matriz para o mapeamento dos componentes da lateral

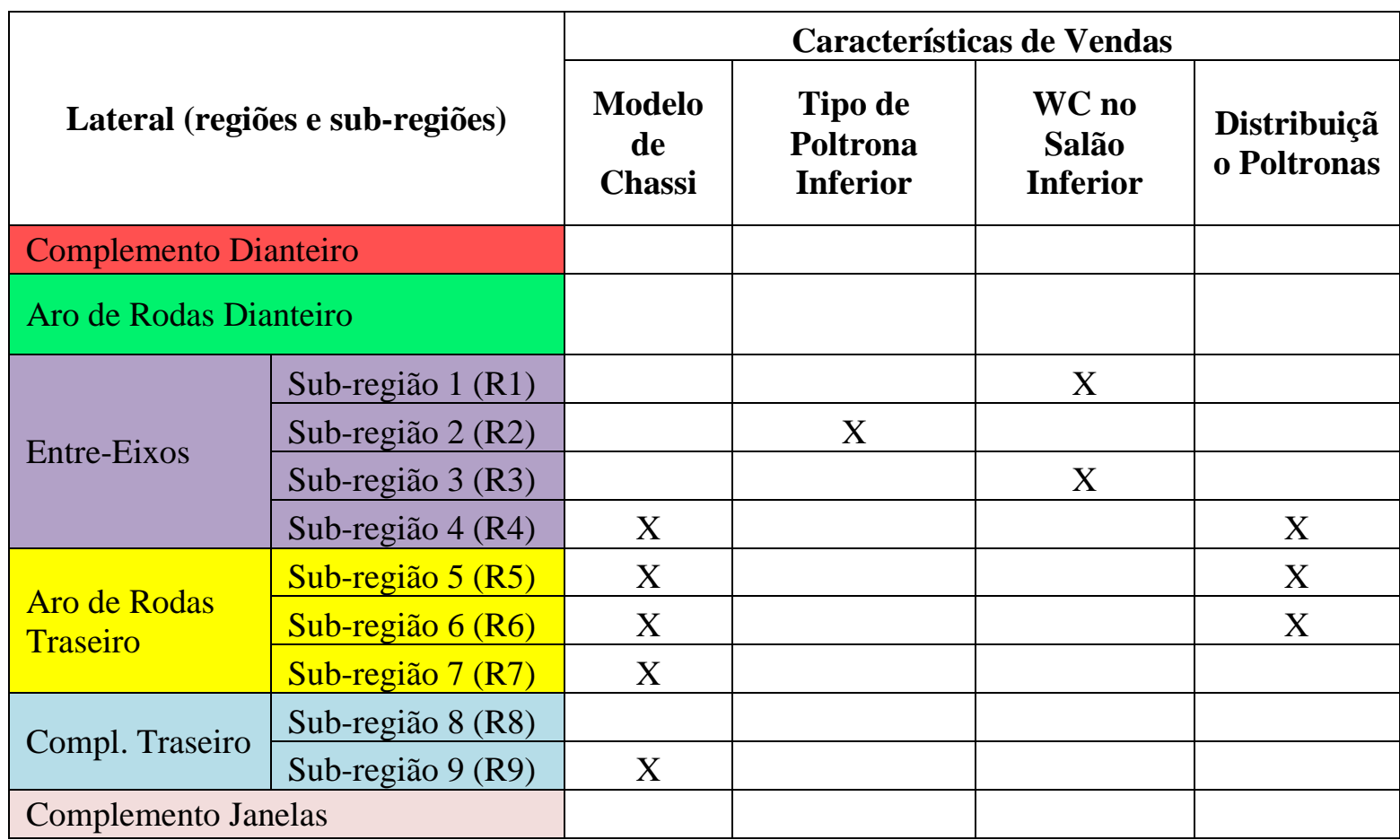

\subsubsection{Estrutura de Funções.}

O objetivo da estrutura de funções é desdobrar a função global do produto em subfunções de menor complexidade para a posterior busca das soluções em cada uma delas (PAHL et al., 2013).

Para o projeto da carroceria, a função global determinada é o desenvolvimento da própria carroceria, onde a sua estrutura de funções é o caminho que deve ser percorrido para o desenvolvimento de seus conjuntos. A Figura 8 ilustra o desdobramento da função global em conjuntos de menor complexidade, o resultado da união dos projetos de cada conjunto é o pacote completo do projeto final da estrutura da carroceria. 
A ordem de concepção para cada um desses conjuntos deve ser respeitada, pois a determinação do primeiro tem influência na determinação do segundo e assim sucessivamente. A análise das funções permitiu dividir o projeto da carroceria em três sistemas funcionais:

- Sistema casulo: possui os conjuntos portadores da função estrutural principal da carroceria, de característica dominante, ou seja, influenciam diretamente nos demais conjuntos.

- Sistema de acoplamento: conjuntos portadores da função principal, mas com a função de interface e união do chassi com o casulo.

- Sistema auxiliar: integra os conjuntos portadores da função secundária. É consequência do que já foi definido pelos sistemas principais.

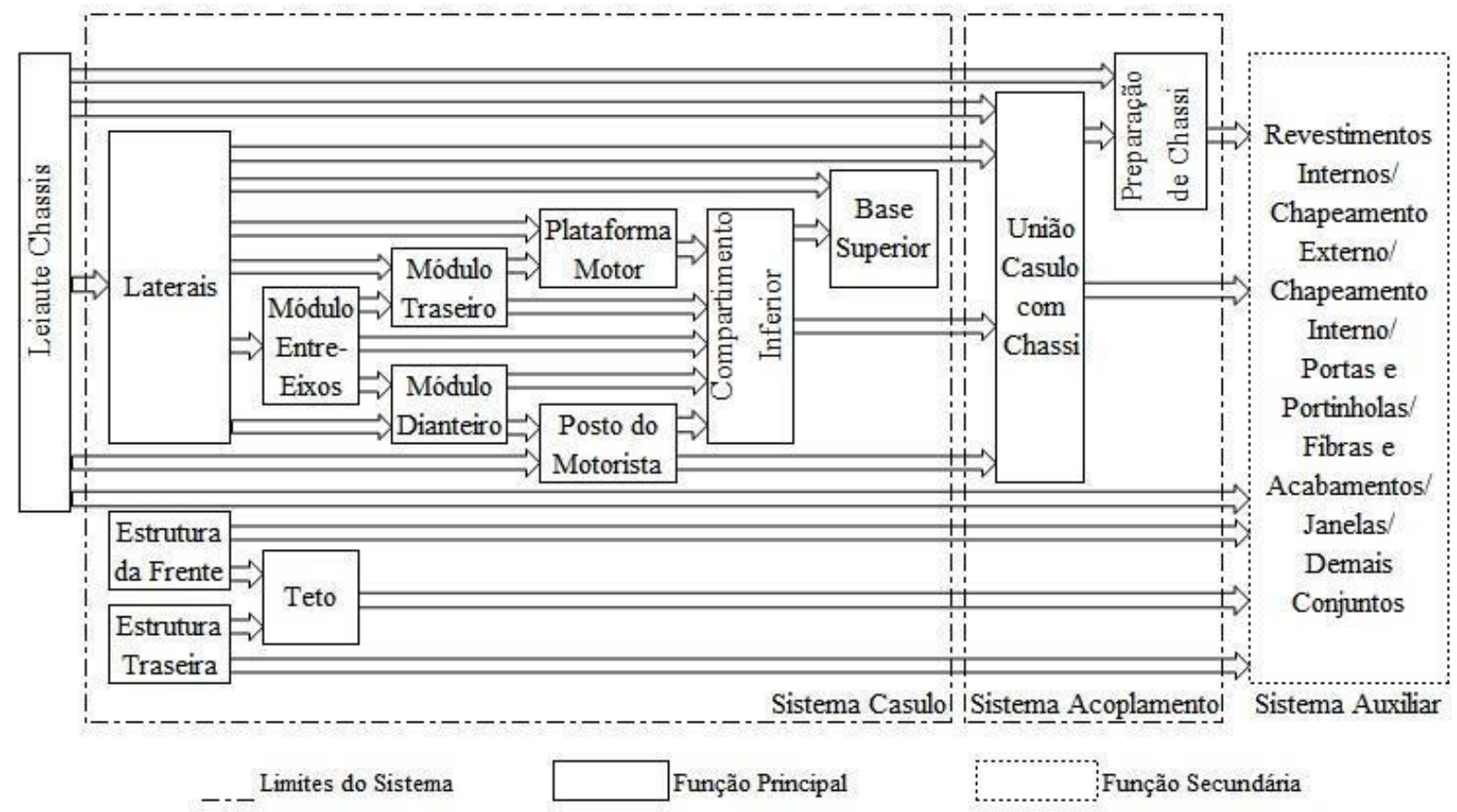

Figura 8 - Estrutura funcional para o projeto

\subsubsection{Concepção das soluções.}

Uma característica do projeto modular é oferecer uma maior variedade de configurações com um menor número de componentes, para isso é necessário identificar elementos independentes e intercambiáveis entre si (PAHL et al., 2013).

O desafio na concepção do ônibus é desenvolver uma carroceria que ofereça a maior gama de configurações combinada com um projeto mais padronizado possível. Portanto, sabendo que a variável chassi é a configuração que mais impacta, foi proposta uma lista de soluções para minimizar esse impacto na determinação da estrutura.

A Figura 9 apresenta as diferentes soluções propostas com o objetivo de encontrar uma concordância entre os pontos de amarração dos três modelos de chassis para conceber um módulo inferior traseiro (região mais influenciada pelo modelo de chassi) mais padronizado. Na Figura 9, os chassis são apresentados, respectivamente, de cima para baixo: Mercedes-Benz (MBB), Scania e Volvo. As carrocerias estão representadas em azul e alinhadas entre si, a linha vertical vermelha indica o alinhamento entre os chassis. Na primeira linha o balanço traseiro possui três variantes de soluções representadas pelas colunas A, B e C, cada uma delas apresenta um alinhamento diferente entre os três modelos. 


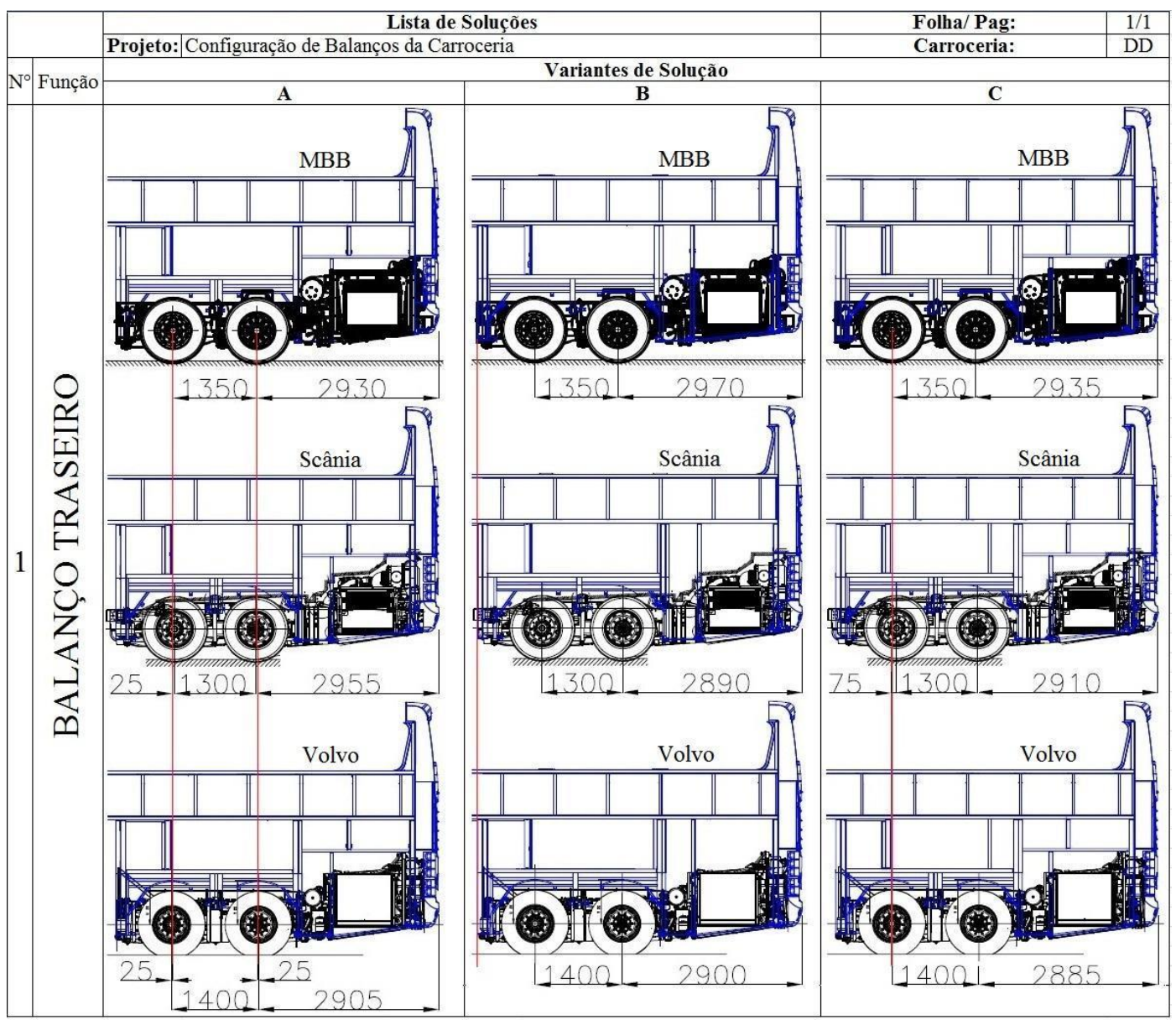

Figura 9 - Lista de soluções para o projeto

A solução "A" propõe um alinhamento centralizando os rodados. A solução "B" sugere um alinhamento entre as cabeceiras, local de união da estrutura do entre-eixos com o chassi. Já a solução "C", alinha os chassis MBB e Volvo, mas desloca $75 \mathrm{~mm}$ para trás o modelo Scania.

Todas as soluções são possíveis para a carroceria, embora cada uma delas proporcione diferentes resultados para o projeto.

\subsubsection{Avaliação das Variantes.}

Para a correta escolha das soluções propostas é preciso atribuir critérios para avaliação, são eles em ordem de prioridade: padronização da estrutura, distribuição das poltronas, peso da carroceria e volume de bagageiro.

Cada critério é influenciado de maneira diferente por cada uma das variantes de solução A, B e C. Para auxiliar nesta escolha foi utilizado o método de Pugh, que consiste em uma análise quantitativa com atribuição de pesos para os critérios, esta avaliação está representada na Tabela 4 (BACK et al., 2008).

A primeira coluna apresenta os quatro critérios, os quais foram divididos em subitens, proporcionando uma análise mais minuciosa. A terceira coluna indica os pesos atribuídos para cada um deles.

As demais colunas representam as variantes de solução A, B e C. O sinal positivo (+), o negativo (-) e o valor (0) indicam respectivamente que a solução em questão é melhor, pior ou não possui influência no critério analisado em relação ao projeto original, ou seja, o quanto ela é mais eficaz em relação à configuração atual. 
Analisando o resultado da Tabela 4 é possível verificar que a solução "A" proporciona uma boa capacidade de padronização, no entanto, possui a menor distância entre eixos entre as soluções, reduzindo a quantidade de lugares no salão.

Tabela 4 - Lista de avaliação das variantes de solução para o projeto

\begin{tabular}{|c|c|c|c|c|c|c|}
\hline \multirow{2}{*}{\multicolumn{3}{|c|}{$\frac{\text { Critérios de Avaliação }}{\text { Adotados }}$}} & \multirow[b]{2}{*}{ Pesos } & \multicolumn{3}{|c|}{ Variantes de Solução } \\
\hline & & & & A & B & C \\
\hline \multirow{6}{*}{ Modularização } & \multicolumn{2}{|c|}{ Balanço Dianteiro } & 0,5 & 0 & 0 & 0 \\
\hline & \multicolumn{2}{|c|}{ Rodado Dianteiro } & 0,5 & 0 & 0 & 0 \\
\hline & \multicolumn{2}{|l|}{ Entre-eixos } & 0,5 & - & + & + \\
\hline & \multicolumn{2}{|l|}{ Rodado Traseiro } & 0,5 & + & - & + \\
\hline & \multicolumn{2}{|l|}{ Balanço Traseiro } & 0,5 & + & - & + \\
\hline & \multicolumn{2}{|c|}{ Plataforma Motor } & 0,5 & + & - & + \\
\hline \multirow{2}{*}{$\begin{array}{l}\text { Configuração } \\
\text { de Poltronas }\end{array}$} & \multicolumn{2}{|c|}{ Quantidade de Lugares } & 0,33 & - & + & 0 \\
\hline & \multicolumn{2}{|c|}{ Espaçamento Poltronas } & 0,33 & 0 & + & 0 \\
\hline \multirow{7}{*}{$\begin{array}{l}\text { Distribuição } \\
\text { Peso da } \\
\text { Carroceria }\end{array}$} & Peso & $\mathrm{MBB}$ & 0,17 & - & 0 & - \\
\hline & Eixo Dianteiro & Scania & 0,17 & + & 0 & 0 \\
\hline & & Volvo & 0,17 & 0 & - & - \\
\hline & Peso & MBB & 0,17 & + & 0 & + \\
\hline & Eixo Traseiro & Scania & 0,17 & - & 0 & 0 \\
\hline & & Volvo & 0,17 & 0 & + & + \\
\hline & Carga Máx. Che & & 0,17 & + & + & + \\
\hline \multicolumn{3}{|c|}{ Volume de Bagageiro } & 0 & 0 & + & 0 \\
\hline & \multicolumn{3}{|c|}{ Soma de (+) multiplicado pelo peso } & 2,01 & 1,5 & 2,51 \\
\hline \multicolumn{4}{|c|}{ Soma de (-) multiplicado pelo peso } & 1,17 & 1,67 & 0,34 \\
\hline \multicolumn{4}{|c|}{ Soma de (0) } & 6 & 6 & 6 \\
\hline \multicolumn{4}{|c|}{ Resultado Final (+) + (-) } & $\mathbf{0 , 8 4}$ & $-0,17$ & 2,17 \\
\hline
\end{tabular}

A solução "C" é a que melhor atendeu aos critérios de avaliação entre as três soluções propostas, a qual proporcionou uma maior capacidade de padronização, critério de maior importância do projeto. Os valores de tamanho de entre eixos e da distribuição de peso foram melhores que a solução "A", mas inferiores em relação a "B". Como ponto negativo ficou com o menor volume de bagageiro entre as soluções. No entanto, o volume de bagageiro é o critério de menor relevância para o projeto. Portanto, foi escolhida a solução "C" para prosseguir com seu desenvolvimento.

\subsubsection{Concretização da Variante de Solução.}

Após a escolha da melhor variante de solução, o próximo passo é a materialização desta a fim de possibilitar uma análise mais detalhada. A concretização dessa variante deve conter apenas o essencial, ou seja, utilizar elementos representativos na sua montagem para representação dos limites do sistema, ligações, mecanismos ou estruturas ainda não definidas, isso ajuda a economizar esforços com detalhes minuciosos do projeto nessa fase (PAHL et al., 2013)

A nova concepção para a carroceria proporcionou um projeto desvinculado do chassi, ou seja, é possível selecionar qualquer um dos três modelos de chassi sem promover alterações na estrutura principal. A Figura 10 simula a nova interface da carroceria para os três modelos de chassis: Mercedes-Benz, Scania e Volvo respectivamente. 


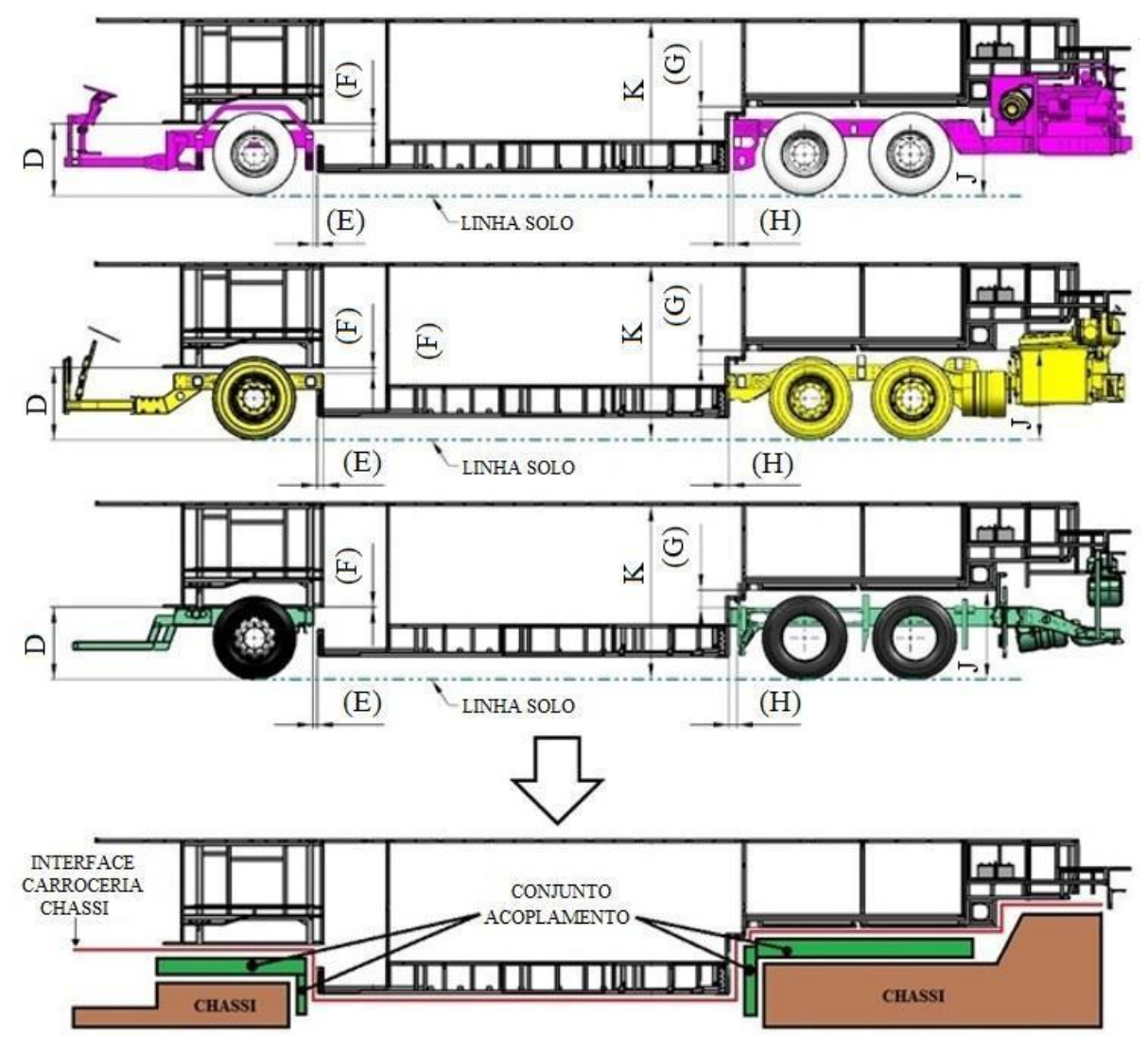

Figura 10 - Concretização do projeto da carroceria

Os valores representados pelas cotas D, J e K estão referenciados na linha do solo e são fixos, não variando de um modelo de chassi para o outro. Quem absorve essa diferença são as dimensões representadas pelas cotas $\mathrm{E}, \mathrm{F}, \mathrm{G}$ e $\mathrm{H}$. As diferenças representadas pelos valores $\mathrm{E}, \mathrm{F}, \mathrm{G}$ e $\mathrm{H}$, dão origem aos conjuntos quais absorvem a variação, concentrando toda a diferença de altura e posicionamento de acoplamento.

Dessa maneira, as variantes que antes estavam ligadas diretamente nos módulos da estrutura principal da carroceria são transferidas para conjuntos de união, denominados conjuntos de acoplamento. $\mathrm{O}$ esquema na parte inferior da Figura 10 simula o novo conceito, qual a mesma estrutura pode ser acoplada em diferentes chassis sem sofrer alterações.

\subsection{Anteprojeto (Fase 3).}

A gama de informações cresce à medida que o projeto do produto é configurado, gerando a necessidade de gerenciar essas informações e tomar decisões no projeto (EDWARDS, 2002).

A introdução dos conceitos DFMA (design for manufacturing and assembly) nessa fase pode otimizar o projeto de maneira a facilitar o processo de fabricação e montagem. Estas diretrizes de projeto inicialmente sugerem uma simplificação na estrutura do produto e, posteriormente, indicam detalhes no desenho dos componentes para a minimização de custos com a fabricação (BOOTHROYD, 2002).

A partir da concepção dos módulos para a carroceria foi proposto um modelo de sistema modular e misto para a configuração dos pedidos, este representado pela Figura 11.

Os quatro primeiros blocos são obrigatórios e constituem o sistema modular. A inserção do quinto bloco permite maior flexibilidade ao projeto, dando origem a um sistema misto. 


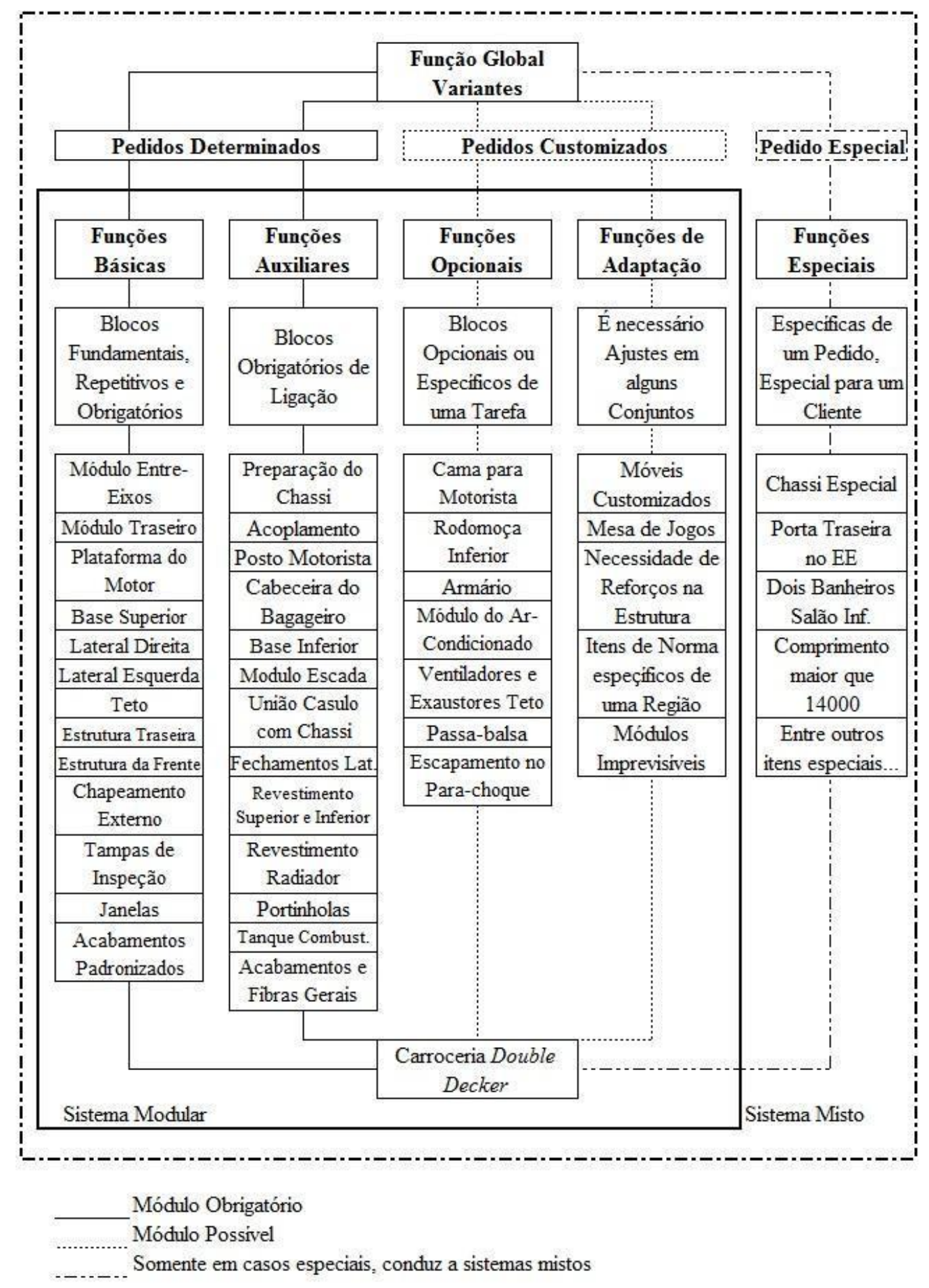

Figura 11 - Sistema modular e misto para o projeto

Cada bloco contém conjuntos com uma determinada função:

- Funções básicas: blocos fundamentais para funcionamento do projeto, repetitivos, obrigatórios e padrões, não variam conforme o pedido.

- Funções auxiliares: blocos obrigatórios de ligação, os quais variam de acordo com uma configuração específica. Por exemplo, a preparação de chassi e a união casulo com chassi, os quais estão diretamente vinculados ao modelo de chassi, funcionando como conjuntos que conectam o mesmo à carroceria, absorvendo as variações de um modelo para o outro. 
- Funções opcionais: blocos opcionais específicos de uma característica, ou seja, podem ser estruturados ou não.

- Funções de adaptação: é necessário ajuste em alguns conjuntos em razão da imprevisibilidade do pedido do cliente.

- Funções especiais: específicas de um pedido, customização total do projeto para atender uma exigência de um cliente. Conduz a sistemas mistos que tem como ponto de partida os conjuntos do sistema modular.

A próxima etapa determina os conjuntos portadores da função global, configurando-os de forma completa, ou seja, especificando material e formato, elementos de fixação, dobradiças, mecanismos, entre outros detalhes.

\subsubsection{Construção do Protótipo.}

A elaboração de um protótipo para testes e avaliação do projeto é uma etapa fundamental do anteprojeto (BACK et al., 2008). Antes de prosseguir com o desenvolvimento e produção da carroceria é de extrema importância a realização de um teste experimental.

Em virtude de ter como objetivo o projeto de uma carroceria qual pode ser acoplada em diferentes modelos de chassis, foi decidido realizar um protótipo da estrutura principal, o casulo. No entanto, essa estrutura precisou ser fabricada separadamente do chassi, para posteriormente ser acoplada.

Como o processo de montagem atual da carroceria parte do chassi preparado, foi necessário utilizar a técnica PKD (partial knocked down), para a fabricação independente do casulo por meio de um carro móvel.

A geometria do carro móvel simula a interface de ligação do chassi com a carroceria, mantendo os valores D, K e J (Figura 10) constantes. A Figura 12 apresenta essa montagem.

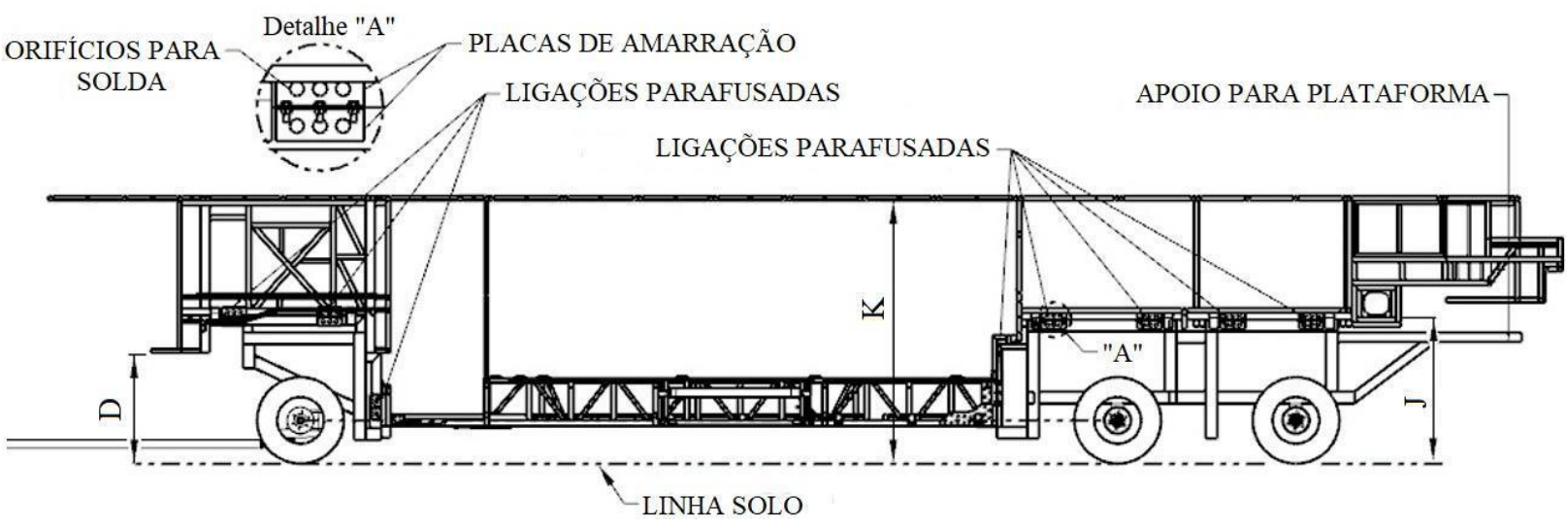

Figura 12 - Esquema de ligação da estrutura móvel para o protótipo

\subsubsection{Fabricação e teste do protótipo.}

A Figura 13a apresenta a construção da carroceria protótipo sobre o carro móvel. Os chassis definidos para o teste foram o chassi Mercedes-Benz O500 RSD 6x2 e o chassi Volvo B11R 6x2, escolhidos pelo fato de representarem a interface de acoplamento mais crítica. A estratégia elaborada para a realização dos testes de acoplamento contou com dois guindastes a fim de efetuar o 
levantamento e movimentação da estrutura da carroceria em direção ao chassi conforme apresentado na Figura $13 b$.

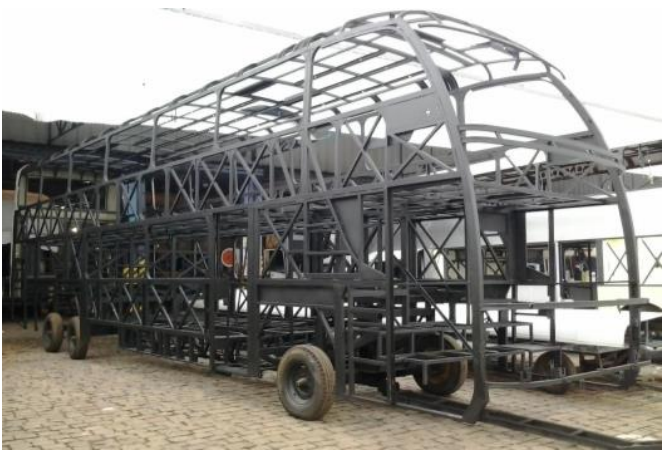

(a)

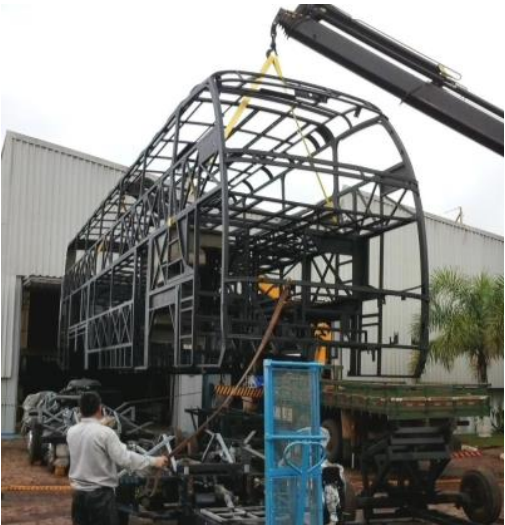

(b)

Figura 13 - Montagem final da carroceria protótipo e acoplamentos nos chassis

O acoplamento do casulo protótipo foi realizado sobre o chassi Mercedes-Benz, e posteriormente, o mesmo processo repetiu-se para o acoplamento sobre o chassi Volvo, representados respectivamente na Figura 14. Após a realização de cada acoplamento, foi dado início a etapa de avaliação do protótipo por parte da engenharia de desenvolvimento, engenharia de processos, qualidade e demais setores envolvidos.
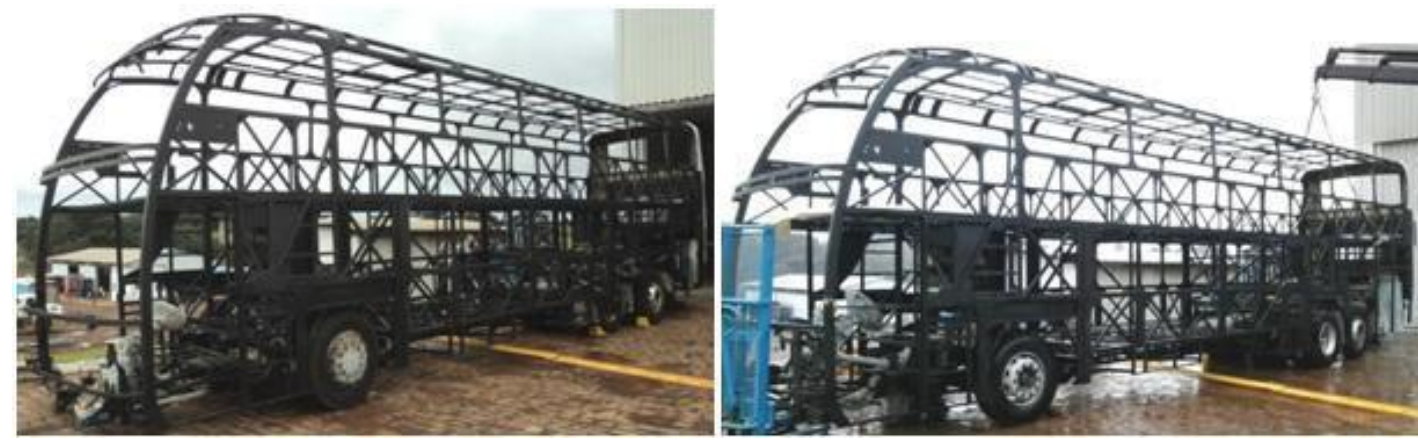

Figura 14 - Acoplamento do casulo nos chassis Mercedes-Benz e Volvo B11R, respectivamente

Após a aprovação do protótipo, o desenvolvimento do projeto prossegue com a finalização do projeto dos conjuntos de função principal, realizando atualizações e provendo melhorias em relação aos problemas encontrados durante os testes práticos, para posterior detalhamento para produção.

\subsection{Projeto Detalhado (Fase 4)}

$\mathrm{Na}$ fase de detalhamento do projeto para produção, é realizado o projeto dos conjuntos portadores da função auxiliar de forma compatível com os conjuntos principais já definidos, como revestimentos internos, chapeamento, portas e portinholas, mecanismo do estepe, entre outros. A Figura 15 ilustra a montagem final da carroceria em 3D, com todos os elementos que constituem o projeto. 


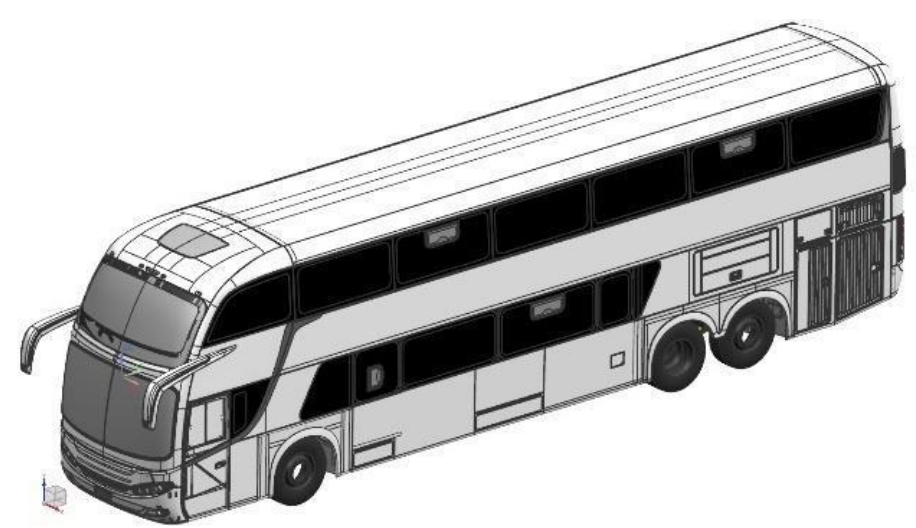

Figura 15 - Projeto final da carroceria em 3D

Após a conclusão do projeto 3D, inicia a elaboração dos desenhos técnicos de cada peça ou conjunto de peças, onde são inseridas cotas, lista de materiais, acabamentos superficiais, tolerâncias dimensionais e geométricas, ajustes e interferências, documentos para auxiliar a produção como desenhos esquemáticos, instruções de montagem, entre outros.

\section{DISCUSSÃO.}

Um dos resultados mais importantes na aplicação do método no projeto foi a padronização alcançada na estrutura da carroceria, a qual atingiu um valor de 70,4 \% para o novo arranjo estrutural, vantagem qual permite determinar um grande volume de componentes e conjuntos com pouquíssimas informações de entrada. Da mesma forma que o modelo de chassi, antes tratado como característica determinante para início do projeto, agora pode ser escolhido por último, impactando em apenas 10,3 $\%$ da estrutura. A Figura 16 ilustra visualmente a diferença entre o novo projeto com relação ao atual.

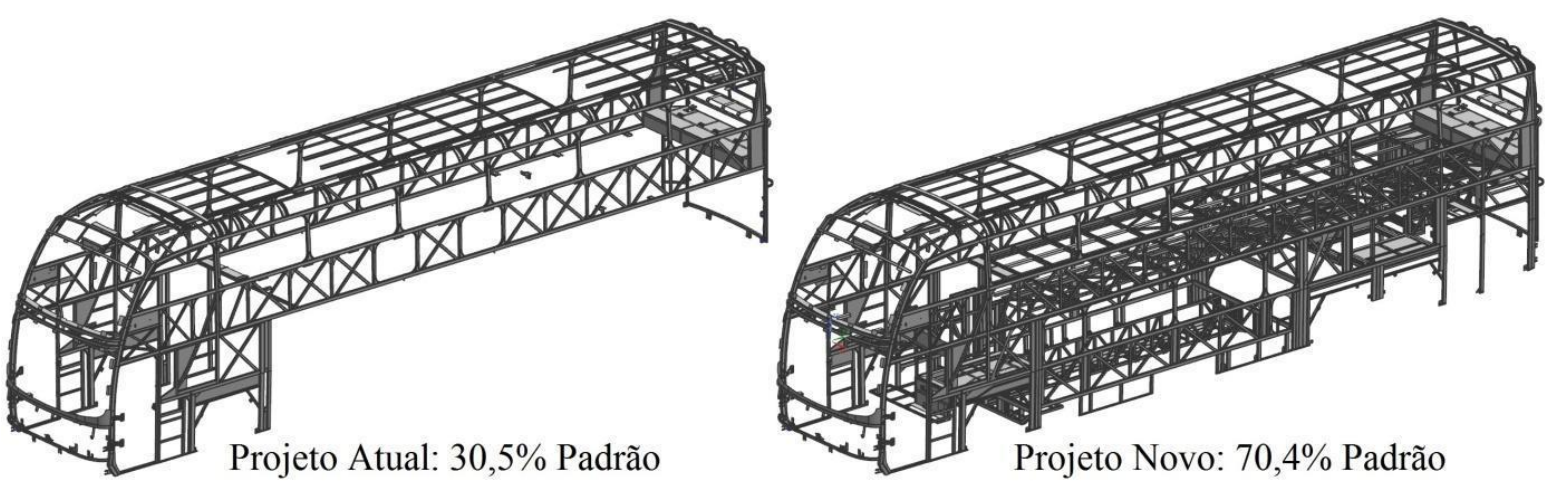

Figura 16 - Padronização final da estrutura para a nova carroceria

A padronização da estrutura refletiu sobre o projeto completo da carroceria. A Figura 17 apresenta a distribuição do projeto final dentro do sistema modular elaborado para a configuração dos pedidos para o cliente.

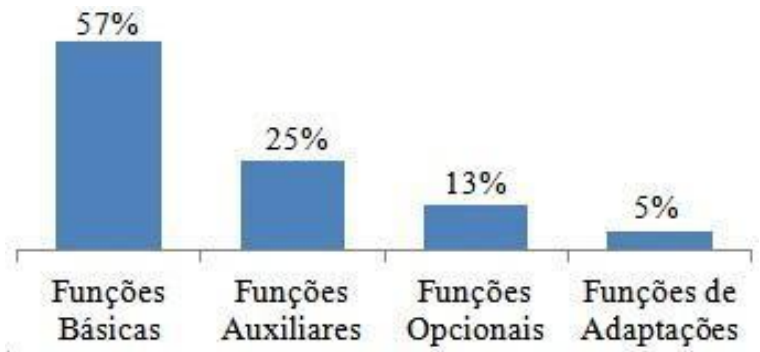

Figura 17 - Distribuição final do projeto da carroceria no sistema modular 
Aproximadamente $57 \%$ do projeto ficou constituído por conjuntos padrões e repetitivos, $25 \%$ constituído por conjuntos obrigatórios de ligação determinados de acordo com as configurações da carroceria, restando apenas $18 \%$ para estudo e elaboração do projeto referente a opcionais e itens customizados para atender a necessidades do cliente.

Outro resultado expressivo foi uma grande redução no impacto que os opcionais do pedido proporcionavam no projeto da estrutura, destacando o modelo de chassi, dos 16 conjuntos quais esta configuração impactava, agora apenas três conjuntos da carroceria sofrem influência do modelo de chassi determinado.

A média de tempo dos projetos atuais é equivalente a $52 h$, o novo tempo para realização do projeto de um pedido ficou estimada em 13,46 $h$, ganho devido ao pequeno volume de trabalho restante aos projetistas para a determinação dos blocos construtivos faltantes, representados na Figura 17 pelos blocos de função opcional e de adaptação, que somados representam apenas $18 \%$. Considerando os tempos de estudo, verificação e liberação do pedido, a nova média não deve ultrapassar a 19,2 $h$, o que deverá reduzir o tempo de projeto para execução dos pedidos em aproximadamente $37 \%$.

O projeto modular e a consequente redução no número de configurações de vendas proporcionaram também uma redução em aproximadamente $78 \%$ no número de conjuntos necessários para atender as diferentes configurações de projeto, dos 355 conjuntos quais eram necessários para suprir toda a variedade de configurações disponíveis, apenas 79 são necessários agora com o novo projeto modular.

\section{CONCLUSÃO.}

Os métodos aplicados no estudo de caso apresentaram bons resultados, como a elaboração de um arranjo estrutural modular para a carroceria com alto grau de padronização, reduzindo ao máximo a influência dos opcionais de venda sobre os conjuntos, diminuindo assim, o tempo de configuração dos pedidos.

O chassi, elemento até então entendido como determinante para início do projeto e do processo de montagem, agora não tem influência sobre a estrutura principal da carroceria, possibilitando a montagem do mesmo casulo em três modelos de chassis diferentes, oferecendo uma nova proposta para a configuração e produção dessas carrocerias, qual permite o projeto e fabricação sem o conhecimento do chassi, evidenciando que a utilização de métodos e técnicas no ciclo de desenvolvimento do projeto proporcionam produtos inovadores e eficazes.

O maior tempo investido nas fases iniciais, aliado a elaboração do protótipo, proporcionou maior assertividade no decorrer do desenvolvimento, aumentando a confiabilidade e diminuindo o tempo gasto com retrabalhos durante o projeto, detalhamento, produção ou problemas que poderiam acontecer já durante o uso do cliente, onde sua ocorrência tem custos bem mais elevados. No entanto, esse maior tempo destinado ao planejamento e concepção não acrescentaram no tempo total de desenvolvimento. Pelo contrário, os mesmos contribuíram para um projeto mais rápido e de maior qualidade.

Aproximadamente $57 \%$ do projeto ficou constituído por conjuntos padrões e repetitivos, $25 \%$ constituído por conjuntos obrigatórios de ligação configurados de acordo com as características da carroceria, restando apenas $18 \%$ para estudo e determinação do projeto referente a opcionais e itens customizados para atender a necessidades do cliente.

De maneira geral, o trabalho realizado verificou na prática, em um ambiente de engenharia, a importância da utilização de métodos no desenvolvimento de produtos, permitindo elaborar um procedimento eficaz para o projeto de carrocerias de ônibus, estendendo-se a diversos produtos e segmentos do mercado, trazendo para as equipes de projeto uma forma mais rápida e organizada de 
trabalho, onde o conhecimento fica registrado e é compartilhado de uma forma possível de ser ensinado e aprendido.

\section{Referências.}

BACK, N. et al. Projeto integrado de produtos: Planejamento, concepção e modelagem. Barueri, SP: Manole, 2008.

BAXTER M. R. Projeto de produto: guia prático para o desenvolvimento de novos produtos. Tradução Itiro Iida - 2 ed. São Paulo, SP: Blucher, 2000.

BOOTHROYD, G. et al. Product Design for Manufacture and Assembly. Taylor \& Francis Group. Second edition, revised and expanded, 2002.

GOMEZ, Luiz Salomão Ribas. Os 4P's do Design: uma proposta metodológica não-linear de projeto. Tese de doutorado, PPGEP/UFSC, 2003.

KAMRANI, A.; SALHIEH, S. Product design for modularity. Springer Science Business Media, LLC. Second edition, 2002.

PAHL, G. [et al]. Projeto na engenharia: fundamentos do desenvolvimento eficaz de produtos, métodos e aplicações. Tradução Hans Andreas Wener, revisão Nazem Nascimento. São Paulo: Edgard Blücher, 2013.

ROZENFELD, H. et al. Gestão de Desenvolvimento de Produtos: Uma Referência para a Melhoria do Processo. São Paulo: Editora Saraiva, 2006

ULLMAN, D. G. The Mechanical Design Process. 3rd ed, Mc Graw-Hill, 2003.

VDI 2221. Systematic Approach to the Design of Technical Systems and Products. Translation of German edition: Verein Deutscher Ingenieure, 1987.

VIERO, C. F. Metodologia de Projeto para arranjo estrutural de carroceria de ônibus através de sistemas modulares: Um estudo de caso. Passo Fundo: Faculdade de Engenharia Mecânica, Programa de Pós Graduação em Projeto e Processos de Fabricação, Universidade de Passo Fundo, Dissertação (Mestrado), 103 p., 2013. 